Chemistry for Colleges and Schools 


\title{
Chemistry for Colleges and Schools
}

\author{
David A. Robinson \\ and \\ John McK. Woollard
}

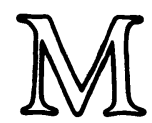


(C) D. A. Robinson and J. McK. Woollard

All rights reserved. No part of this publication may be reproduced or transmitted, in any form or by any means, without permission.

First published 1982 by

THE MACMILLAN PRESS LTD

London and Basingstoke

Companies and representatives throughout the world.

Typeset by Styleset Limited, Salisbury, Wilts.

ISBN 978-1-349-04542-6 ISBN 978-1-349-04540-2 (eBook)

DOI 10.1007/978-1-349-04540-2

Cover photograph by Ron Boardman/Bruce Coleman Limited

The paperback edition of this book is sold subject to the condition that it shall not, by way of trade or otherwise, be lent, re-sold, hired out, or otherwise circulated without the publisher's prior consent in any form of binding other than that in which it is published and without a similar condition including this condition being imposed on the subsequent purchaser. 
For

forever
MOEMEDI

Go

go ya bosakhutleng 


\section{Contents}

Preface

ix

\section{SECTION A: INTRODUCTION}

1 Facts and Laws - Bricks and Mortar

\section{SECTION B: PHYSICAL CHEMISTRY}

2 Thermochemistry - why do chemical reactions occur?

4 Principles of Chemical Equilibrium

5 Heterogeneous Chemical Equilibria - Solubility Products and Precipitation

Acid-Base Equilibria

7 Oxidation-Reduction Reactions/Electrochemistry

8 States of Matter - Gases

9 States of Matter - Condensed Phases

\section{SECTION C: VALENCY AND BONDING}

10 The Atomic Problem

11 An Introduction to Wave Mechanics

12 Atomic Structure

13 Molecules

14 Molecular Orbitals

SECTION D: DESCRIPTIVE INORGANIC CHEMISTRY

18 Periodic Properties

20 Two Important Elements: Hydrogen and Oxygen 
viii Contents

\section{SECTION E: ORGANIC CHEMISTRY}

25 Introduction to Organic Chemistry

26 Hydrocarbons

27 Haloalkanes

Isomerism

29 Oxyalkanes: Alcohols and Ethers

30 Carbon Multiply Bonded to other Atoms

31 Other Carbonyl Compounds

Amines

Useful synthetic reagents

34 Aromatic Chemistry - the principles

Benzene and its Derivatives - I

36 Benzene and its Derivatives - II

\section{APPENDICES}

1 Chemical Names, Symbols and Atomic Masses

2 Work in a Chemical System

3 Standard Thermodynamic Quantities

4 The Derivation of $\Delta S=q / T$

5 The Distribution of Molecular Energy

6 Rate Law for Production of Phosgene: Steady-State Approximation

7 Free Energy Change and the Equilibrium Constant

8 Ionisation Energies 


\section{Preface}

Anyone teaching an introductory chemistry course at college is under pressure from two directions. The growth of the subject means that more and more material has to be taught in later years, and, understandably, lecturers want their students to have a better background in chemistry, including more and more modern material. In the schools the syllabi are constantly being altered and modified, so if students are gathered from a variety of secondary schools to form the intake at college, they have differing backgrounds in chemistry which the teacher must also contend with. Producing a suitable text for an introductory college chemistry course is therefore not easy.

One solution has been to write a text which is as comprehensive as possible, to cater for all the different backgrounds and for all the new areas of knowledge, and then leave the selection of material to the teacher and students. Such a solution is fine in certain circumstances, but there are three criticisms of such an approach. The first is that the vast majority of such comprehensive texts are in fact rather weak in organic chemistry so it is usually necessary to get a supplementary text to fill this gap. The second is simply one of size: the comprehensive text becomes a fearsome giant that acts as a major deterrent to study merely because it is so big, quite apart from the difficult vocabulary and wordy approach adopted by some authors. This complaint becomes especially important in overseas countries where students often study in English as their 'second' language. The third stems from the complexity of the mathematics required to cover modern physical chemistry fully. Given the varied mathematical background of students entering college, many would feel such a text too mathematical and so, for a second reason, incomprehensible. On the other hand, the texts that avoid the mathematics are even longer, and fail to provide a sound basis for later courses in the subject.

We have thus felt there is a need for a single textbook to cover the whole of introductory chemistry. The text should be concise and simply written, but cover as broad a range of material as is possible within these constraints. Inevitably this means that some areas will be emphasised whilst others of lesser importance (in our eyes) will have been scarcely touched upon. We realise that opinions may differ here, but we have tried to devise a framework of concepts and facts into which can be fitted the more detailed theories and data that a student meets later. Obviously it would be foolish and close to impossible to treat chemistry in a non-mathematical way, but to come to terms with the weak mathematical background of some students we have tried to keep the text at a standard so that anyone with GCE ' $O$ ' level would have little difficulty in fully understanding the development of the theories.

We cover the three classical sub-sections of chemistry as follows:

(1) Physical chemistry is presented in terms of the unifying topics of thermodynamics, kinetics, and equilibria: and 'traditional' physical chemistry such as 'states of matter' has been given little space. We have chosen a statistical rather than classical approach to thermodynamics, partly because of its future usefulness, and partly also because classical thermodynamics requires a level of familiarity with differential calculus which the rest of the text does not.

(2) Inorganic chemistry is presented firstly from the point of view of valence and bonding, and then of descriptive inorganic chemistry. A chemist must have a factual familiarity with chemical compounds, to avoid the sort of student who on 'theoretical grounds' expects sodium chloride to be a blue gas: but this familiarity should 
come mainly through laboratory work. We have chosen to emphasise trends, correlations, and patterns, and to cut down on the quantity of purely factual knowledge; both the mass of data that 'fit' the patterns, and the exceptions.

(3) Organic chemistry is covered in considerably greater detail than is usual in a general text. A simplified mechanistic approach is used, so that more advanced courses can build on this knowledge without requiring the student to re-learn a lot of material, and also to get away from the complaint that organic chemistry is just learning'.

We hope the text will meet the requirements of a course book for Introductory General Chemistry courses in universities, colleges, and polytechnics. At various stages of this project we have been assisted by numerous people. In particular we should like to thank J. D. McConnell, I. G. Macfarlane, T. T. Mokoena, and A. T. Hutcheon. It is a pleasure to acknowledge their contributions. Our ideas have been developed whilst teaching the students at UBS, and to them too we owe a debt for providing the spur to write, and for being willing assistants in the early stages of preparing the text.

March 1979

D. A. ROBINSON

J. MCK. WOOLLARD

This book was born out of close collaboration between David Robinson and myself during the course of several years while we were teaching students at UBS. The death of any colleague is a blow, but David's death, in late 1979, came as a particular shock, robbing me of a good friend and trusted colleague. There is no doubt that without his drive and enthusiasm, the writing of this book would never have been started, let alone completed, and it is all the more tragic that he did not live to see the fruit of his labour appear in print. I join with his parents and many other friends in sorrowing over his death and paying tribute to his memory.

J. McK Woollard 